\author{
Geophysical and Lithologic Logs of Seven \\ Test Holes Drilled During 1978 and 1979 \\ In the Pierce Reservoir and Bengough Hill \\ Quadrangles, Albany and Carbon Counties, Wyoming
}

by Dan E. Hansen

Open File Report 80-381

This report is preliminary and has not been edited or reviewed for conformity with U.S. Geological Survey standards. 
CONTENTS

Page

Introduction- 1

References-- 3

Lithologic and Geophysical Logs- 8

ILLUSTRATIONS

Figure 1. Sketch map showing approximate location of drill sites,

Rock Creek coal field, Wyoming- 5

2-3. Dril1-hole location maps, Albany and Carbon Counties, Wyoming:

2. Central part of Pierce Reservoir-Bengough Hill

Quadrangles-_- 6

3. East central part of Pierce Reservoir-Bengough Hill

Quadrangles-- -

TABLE

Table 1. Summary of information for seven drill holes in the Pierce Reservoir and Bengough Hill Quadrangles, Albany and Carbon Counties, Wyoming-_- 


\section{GEOPHYSICAL AND LITHOLOGIC LOGS OF SEVEN TEST HOLES DRILLED \\ DURING 1978 AND 1979 IN THE PIERCE RESERVOIR AND BENGOUGH \\ HILL QUADRANGLES, ALBANY AND CARBON COUNTIES, WYOMING \\ by Dan E. Hansen \\ Introduction}

The U.S. Geological Survey drilled seven test holes during 1978 and 1979, on Federal lands in the Pierce Reservoir and Bengough Hill Quadrangles, T. 19 N., R. 77 W., Rock Creek coal field, Laramie basin, Albany and Carbon Counties, Wyo. as part of the Coal Exploratory Program. The purpose of the drilling was to explore for coal, facilitate correlation of coal beds, and evaluate their thickness and lateral extent. All of the drilling was done in the coal-bearing Upper Cretaceous Medicine Bow Formation, which may be as much as 350 feet thick in this area. The geologic objectives of the drilling were determined by using the geologic mapping by Hyden (1966), a and b.

Drilling was done by $\mathrm{K}$ and $\mathrm{K}$ Drilling, Inc., Montrose Colo. under the supervision of the U.S Geological Survey. Rotary holes were drilled by truckmounted rigs using 5 inch tricone bits and three-way blade bits. Drilling fluids used were air, air-water biodegradable foam, and mud. The holes were filled with heavy mud upon completion and a surface plug of cement placed therein. Drill sites were then reclaimed.

Two of the holes had to be abandoned because of drilling problems, but they were offset a short distance and completed. Hole BH-7A was abandoned because of an extremely large water flow from thick surface gravel. Hole BH2-A was abandoned because of unrecoverable drill pipe in the hole. 
The geophysical logging of one drill hole was done by Nuclear Logging Service Inc., Lafayette, Colo.; three drill holes were logged by the Geological Survey, Lakewood, Colo.; one drill hole was logged by Strata Surveys, Steamboat Springs, Colo.; and two drill holes were logged by Century Geophysical Corp., Casper, Wyo. A general suite of logs consisting of gamma ray, gamma gamma (density) - focused and unfocused, resistivity, and caliper were run. Two of the holes closed immediately after being drilled. Gamma ray and density logs were run through drill pipe in one of the closed holes, but only the gamma ray $\log$ was run in the other hole. In this other hole the density probe malfunctioned, and because of delay due to inclement weather, the hole collapsed before the log could be run.

The geophysical logs in this report were photographically reduced to either 20 or 40 percent of the original size. The reduced vertical scale is about 1 inch to 50 feet. All measurements on the geophysical logs are in feet; to convert to meters multiply by 0.3048 . All but two logs were hand traced before reduction and are not photographic reproductions of the original logs. The two logs not hand traced were reproduced by computer print out to the desired scale.

Lithologic logs are based on field examinations of drill-hole cuttings collected at 5-foot intervals, and lithologic interpretations are adjusted to geophysical logs. 


\section{References}

Hyden, H. J., 1966a, Geologic map of the Pierce Reservoir Quadrangle, Albany and Carbon Counties, Wyoming: U.S. Geol. Survey Geol. Quad. Map GQ-510. Hyden, H. J., 1966b, Geologic map of the Bengough Hill Quadrangle, Albany and Carbon Counties, Wyoming: U.S. Geol. Survey Geol. Quad. Map GQ-579. 
Table 1.--Summary of lnformation for seven holes in the

Pierce Reservoir and Bengough Hill Quadrangles, Albany and Carbon Counties, Wyo.

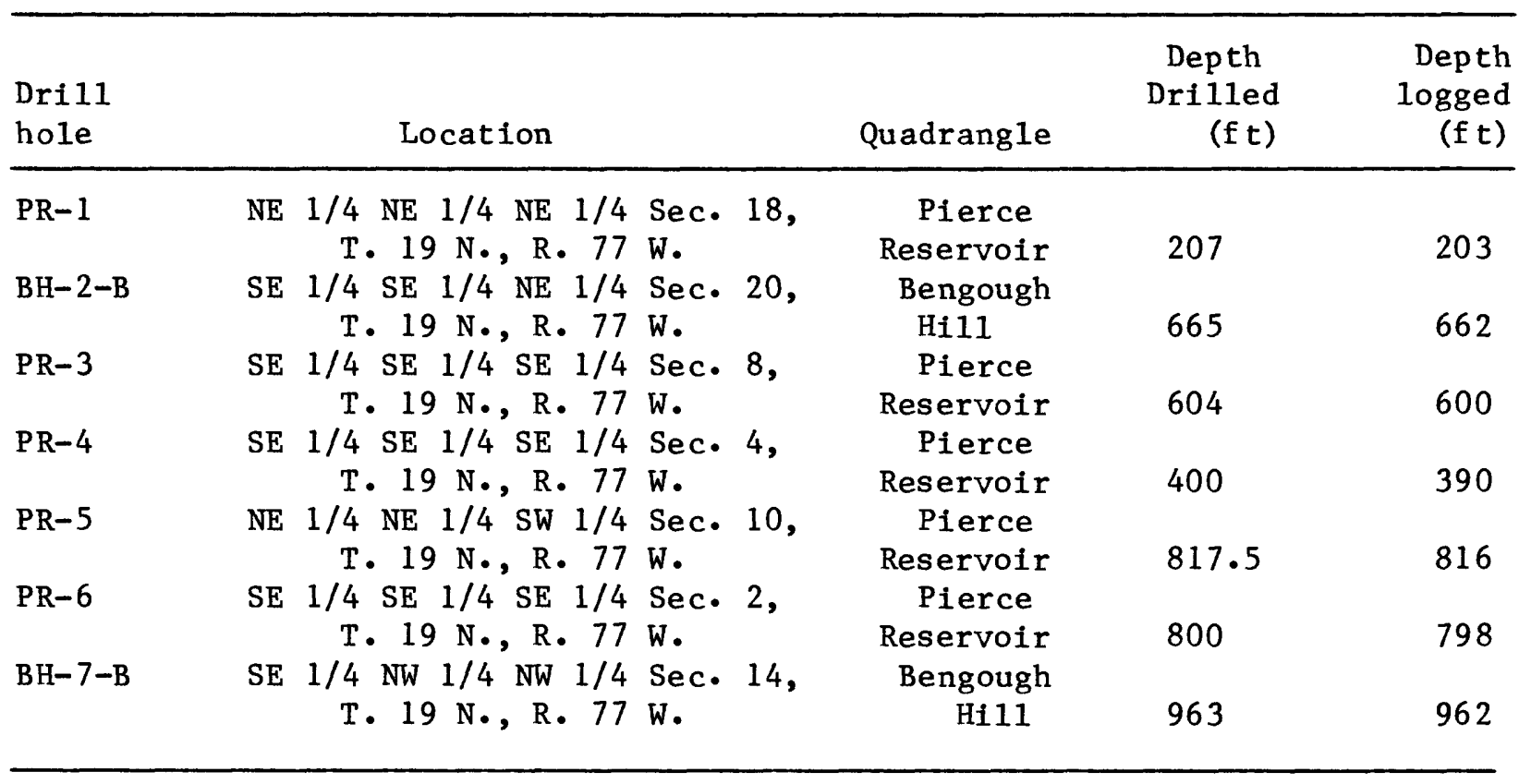




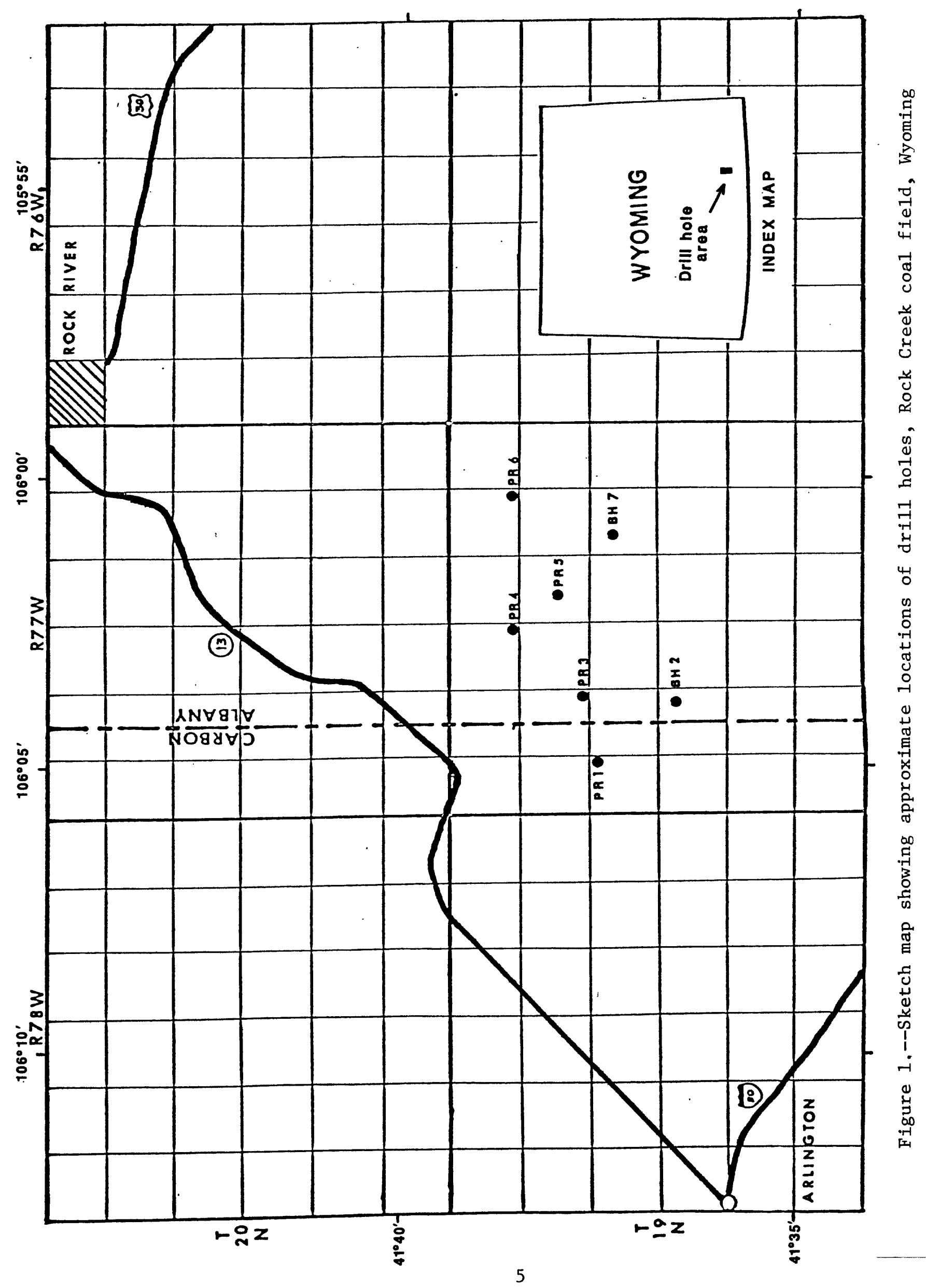




\section{PIERCE RESERVOIR \& BENGOUGH HILL QUADRANGLES}



Figure 2.--Drill hole location map, central part of Pierce Reservoir-Bengough Hill Quadrangles, Albany and Carbon Counties, Wyoming. 


\section{PIERCE RESERVOIR \& BENGOUGH HILL QUADRANGLES}

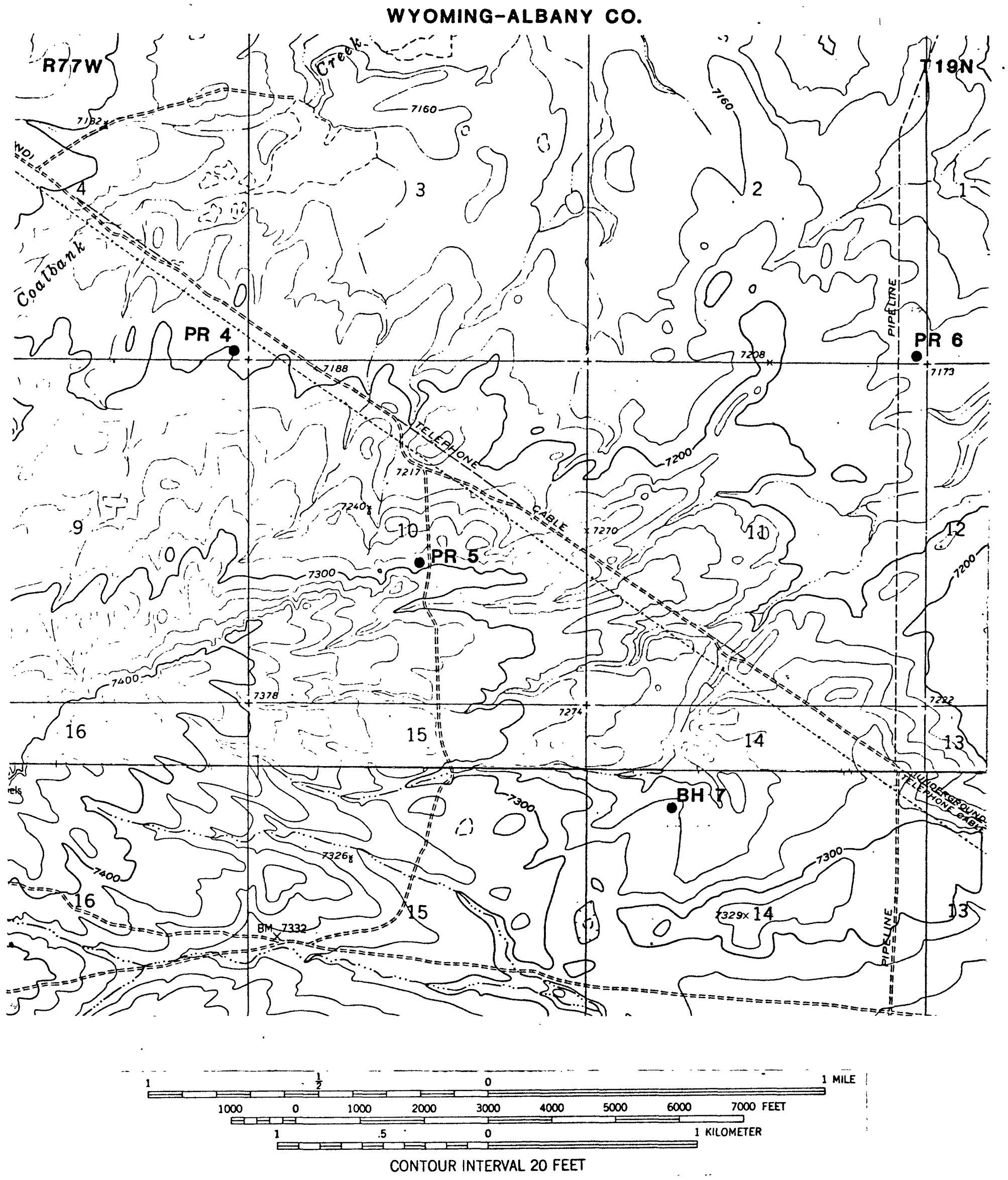

Figure 3.--Drill hole location map, east central part of Pierce Reservoir-Bengough Hill Quadrangles, Albany and Carbon Counties, Wyoming. 


\section{LITHOLOGIC AND GEOPHYSICAL LOGS}

LOCATION NUMBER PR-1

LOCATION NE $\frac{1}{4} \mathrm{NE}^{\frac{1}{4}}$ COUNTY Carbon

CORED YES

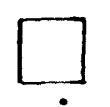

DATE Nov, 26, 1978

Sec. 18 T. 19 N.

STATE Wyoming

INTERVAL ( $s$ )

DRILLING MEDIUM:

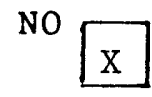

SURFACE ELEVATION(ft) 7335
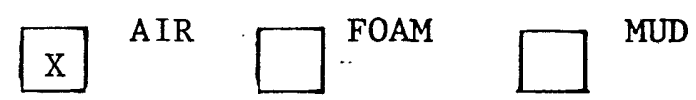

R. 77 W. Quad. Pierce Reservoir TOTAL DEPTH(ft) 207

GEOPHYSICAL LOGS :

Natural Gamma

Gamma Gamma

Resistivity

Caliper

$\begin{array}{ll}\text {; } & \text { Scale } \frac{11 \text { CPS/in }}{1.1 \mathrm{~K} \text { CPS/in }} \\ ; & \text { Scale } \frac{20 \text { OHM/in }}{11 / \text { in }}\end{array}$

Logging Speed Logging Speed

Logging Speed Logging Speed fpm

$\mathrm{fpm}$

fpm fpm

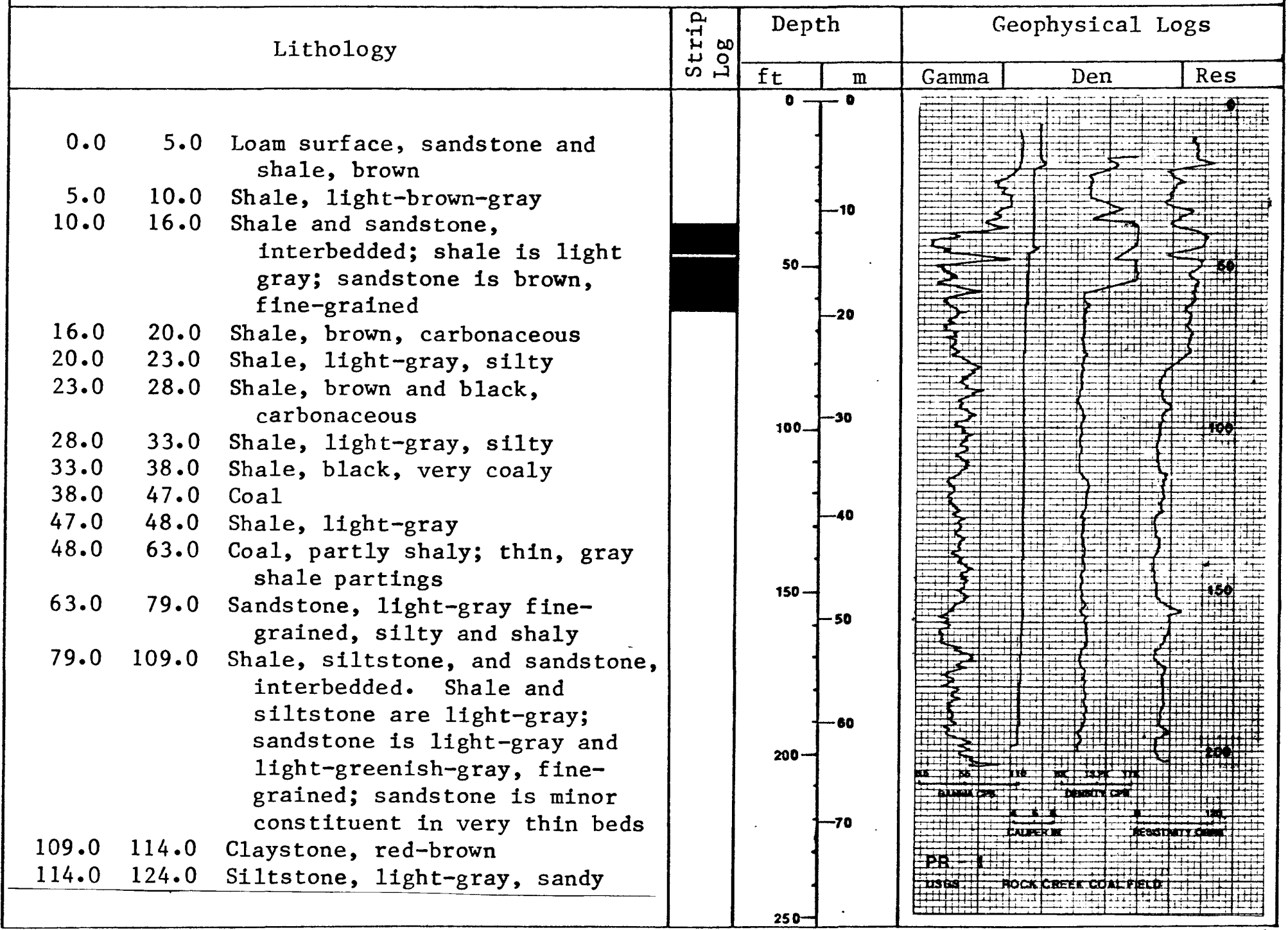




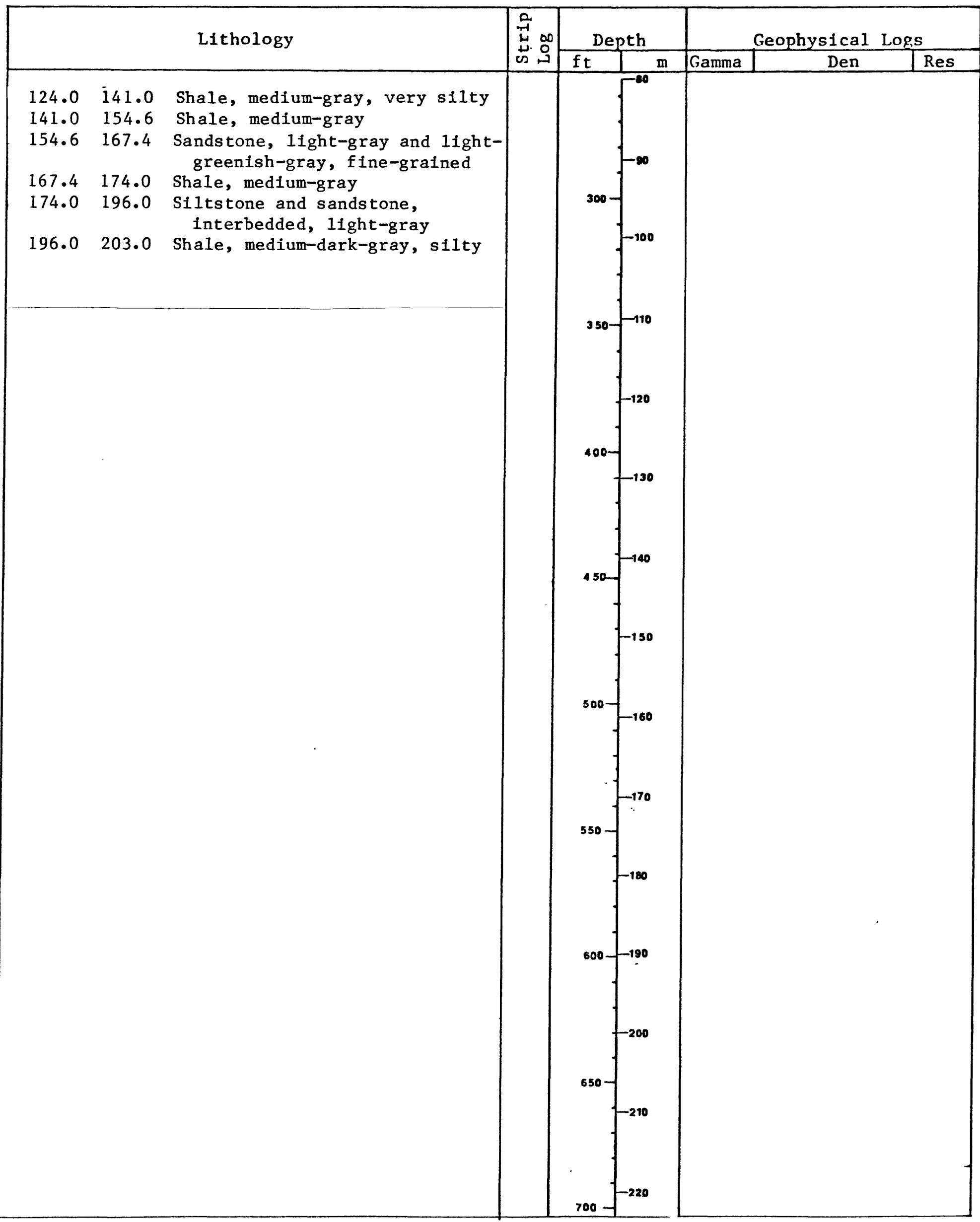


LOCATION NUMBER BH-2-B

LOCATION SE $\frac{1}{4} \mathrm{SE}^{\frac{1}{4}} \mathrm{NE} \frac{1}{4}$

COUNTY Albany

CORED

YES

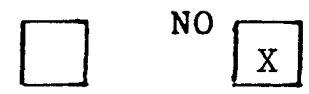

DATE May 5, 1979

Sec. 20 T. 19 N. R. 77 W. Quad. Bengough Hill

STATE Wyoming

TOTAL DEPTH(ft)

662

INTERVAL (s)

$\square^{\text {FOAM }} \mathrm{x}$ MUD $\square$ WATER OBSERVATION WELL

GEOPHYSICAL LOGS :

Natural Gamma

Gamma Gamma

Resistivity

Caliper
; Scale 120 APG/in

; Scale Density G/cc

; Scale 230 OHM M/in

; Scale 1"/in
Logging Speed

Logging Speed

Logging Speed

Logging Speed

\begin{tabular}{ll}
20 & $f \mathrm{pm}$ \\
20 & $\mathrm{fpm}$ \\
\hline 20 & $\mathrm{fpm}$ \\
\hline 20 & $\mathrm{fpm}$ \\
\hline
\end{tabular}

Lithology

0.028 .0 Sandstone, conglomeritic, orange-brown, medium- to coarse-grained with granules and small quartzite pebbles

28.030 .9 Sandstone and siltstone, lightbrown. Sandstone is chiefly coarse-grained

$30.9 \quad 35.8$ Siltstone, light brown

35.843 .1 Sandstone, orange-brown, coarsegrained, silty

43.1 55.6 Siltstone, 1ight-yellow-brown

$55.6 \quad 61.0$ Sandstone, orange-brown, mediumgrained

$61.0 \quad 70.1$ Siltstone, gray

$70.1 \quad 140.0$ Sandstone, conglomeritic, lightgray. Sandstone is fine-to coarse-grained. Granules and sma11 pebbles of white quartzite and pink feldspar

140.0158 .1 Sands tone, light-gray, fine- to coarse-grained

158.1173 .2 Sandstone and conglomerate, light-gray. Sandstone is chiefly coarse-grained. Conglomerate is chiefly of white and pink feldspar and white quartzite; granules and small pebbles

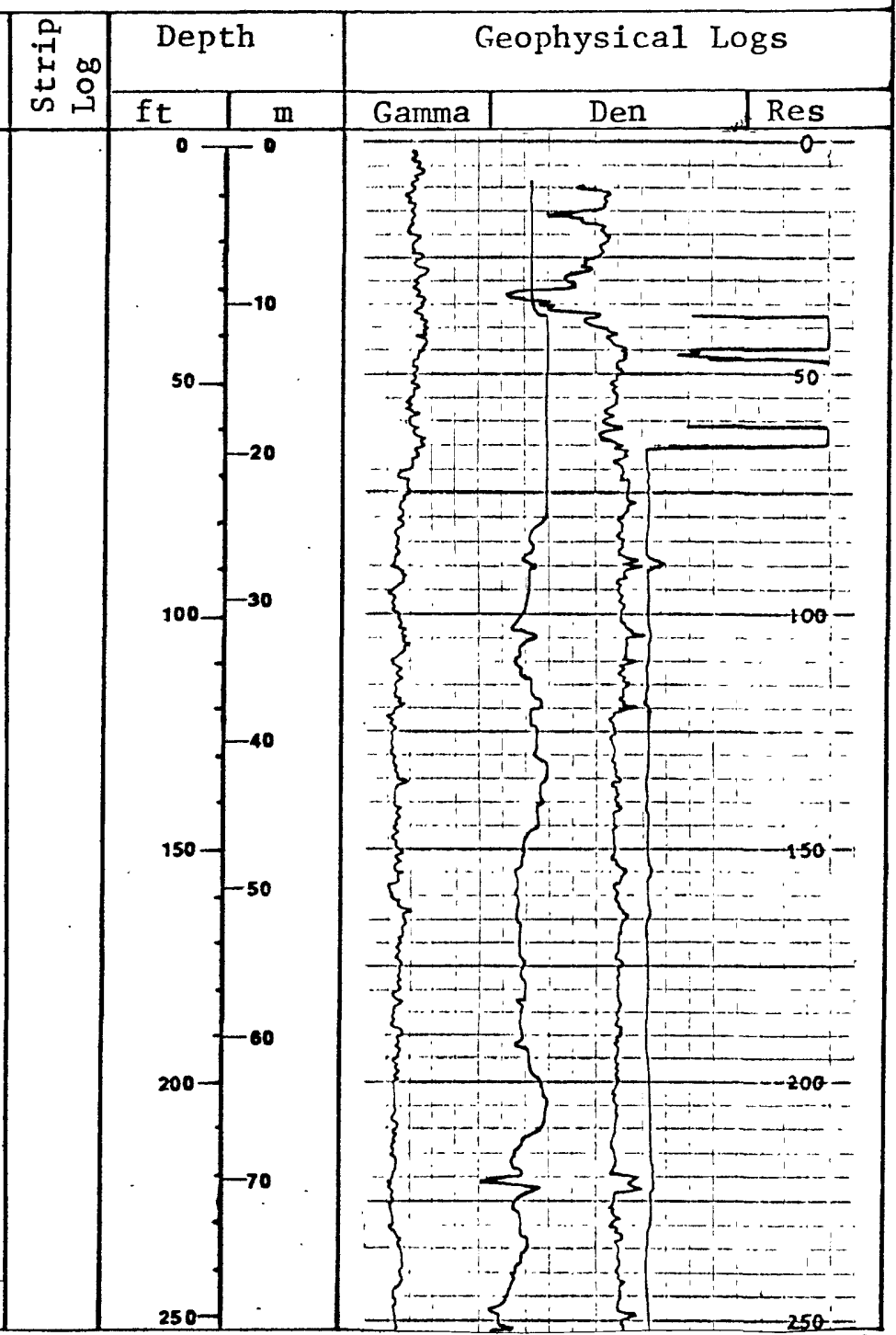




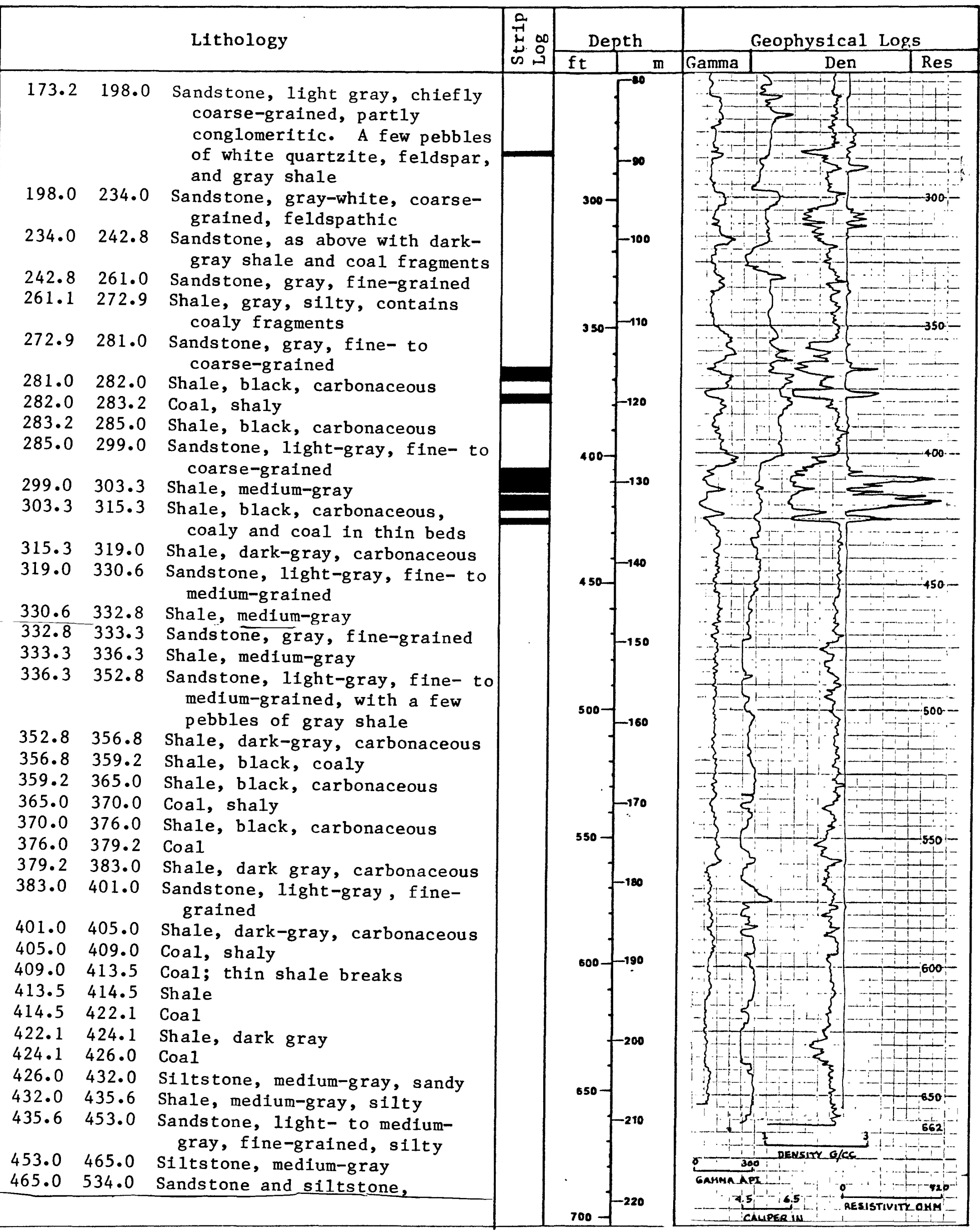




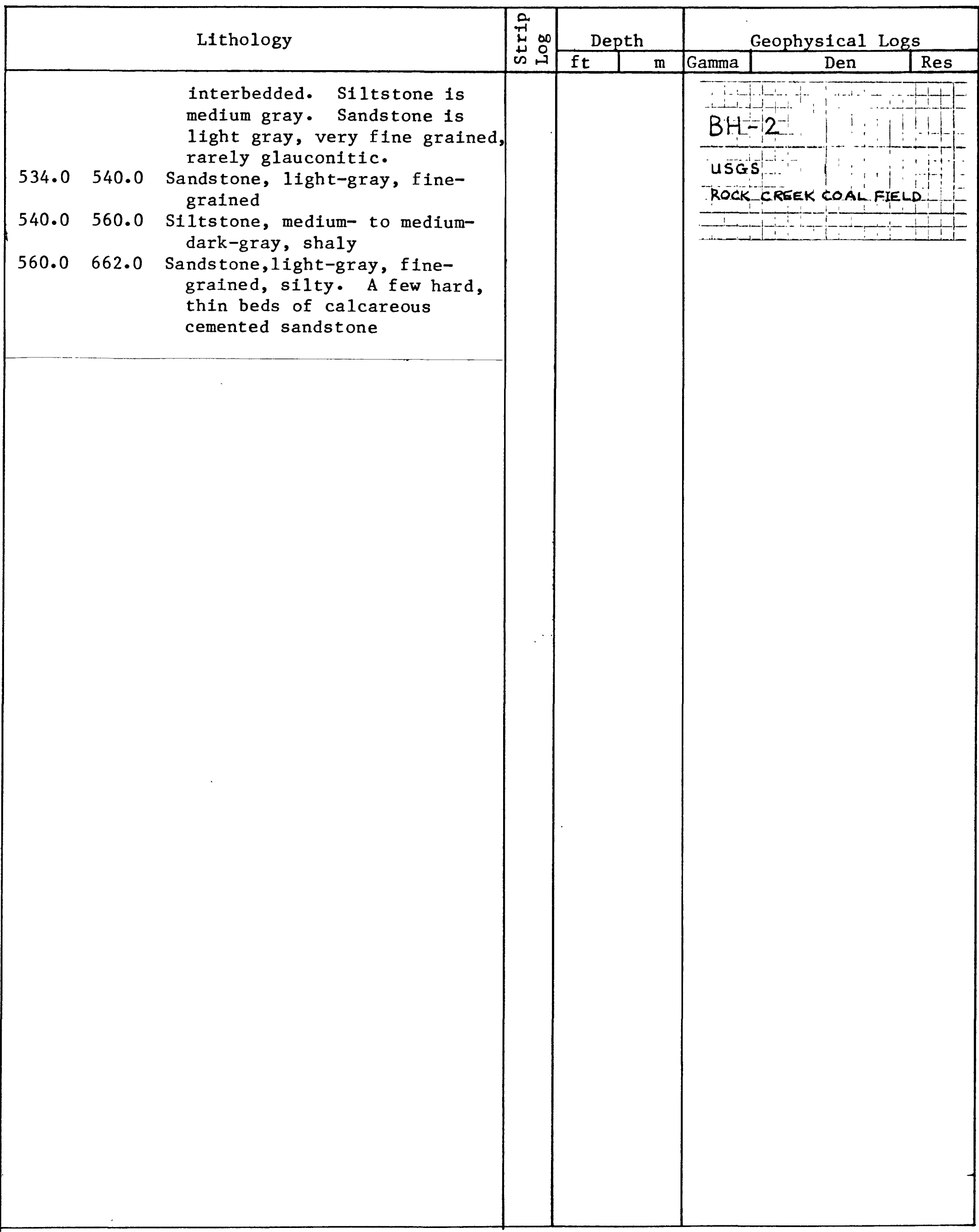




\section{LITHOLOGIC AND GEOPHYSICAL LOGS}

LOCATION NUMBER PR-3

LOCATION $\mathrm{SE}^{\frac{1}{4}} \mathrm{SE}^{\frac{1}{4}} \mathrm{SE}^{\frac{1}{4}}$ COUNTY Albany
DATE Nov. 22, 1978

Sec. 8 T. $19 \mathrm{~N}$.

STATE Wyoming
SURFACE ELEVATION(ft) 7330

R. 77 W. Quad.Pierce Reservoir

TOTAL DEPTH(ft)

604
CORED YES

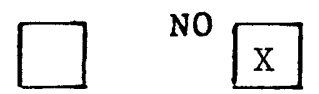

INTERVAL (s)

DRILLING MEDIUM:
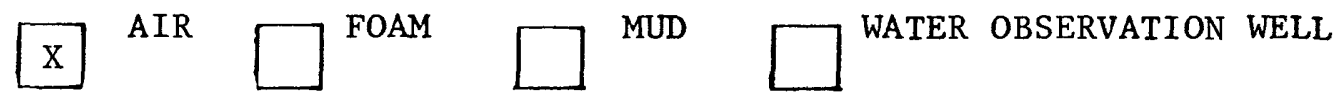

GEOPHYSICAL LOGS :

Natural Gamma

Gamma Gamma

Resistivity

Caliper

$; \quad \begin{array}{ll}\text { Scale } \frac{12 \mathrm{CPS} / \mathrm{in}}{1.27 \mathrm{~K} \mathrm{CPS} / \mathrm{in}} \\ ; \quad \text { Scale } \frac{20 \mathrm{OHM} / \mathrm{in}}{1^{\prime \prime} / \text { in }}\end{array}$

Logging Speed

Logging Speed

Logging Speed

Logging Speed fpm

fpm

fpm fpm
Lithology

0.022 .0 Sandstone, yellowish-brown, fine- to very- coarse-grained and conglomeritic; pebbles and granules of feldspar

22.028 .0 Siltstone, yellowish-brown

28.041 .0 Sandstone, yellowish-brown, fine- to very-coarse-grained; calcite cemented

41.049 .0 Sandstone, medium-brown, finegrained

$49.0 \quad 55.0$ Shale, medium-gray

$55.0 \quad 69.0$ Siltstone, medium-gray, sandy

69.074 .0 Sandstone, light-gray, finegrained

$74.0 \quad 80.0$ Siltstone, medium-gray, sandy

80.085 .0 Sandstone, light-gray, finegrained

85.098 .0 Siltstone, medium-gray, sandy

98.0164 .0 Sandstone, light-gray, fine- to very-coarse-grained, conglomeritic; granules and small pebbles of feldspar; gray shale pebbles from 160.0 to 164.0

164.0168 .0 Sandstone, light-gray, fine- to very-coarse-grained

$168.0 \quad 172.0 \quad$ Shale, medium-gray

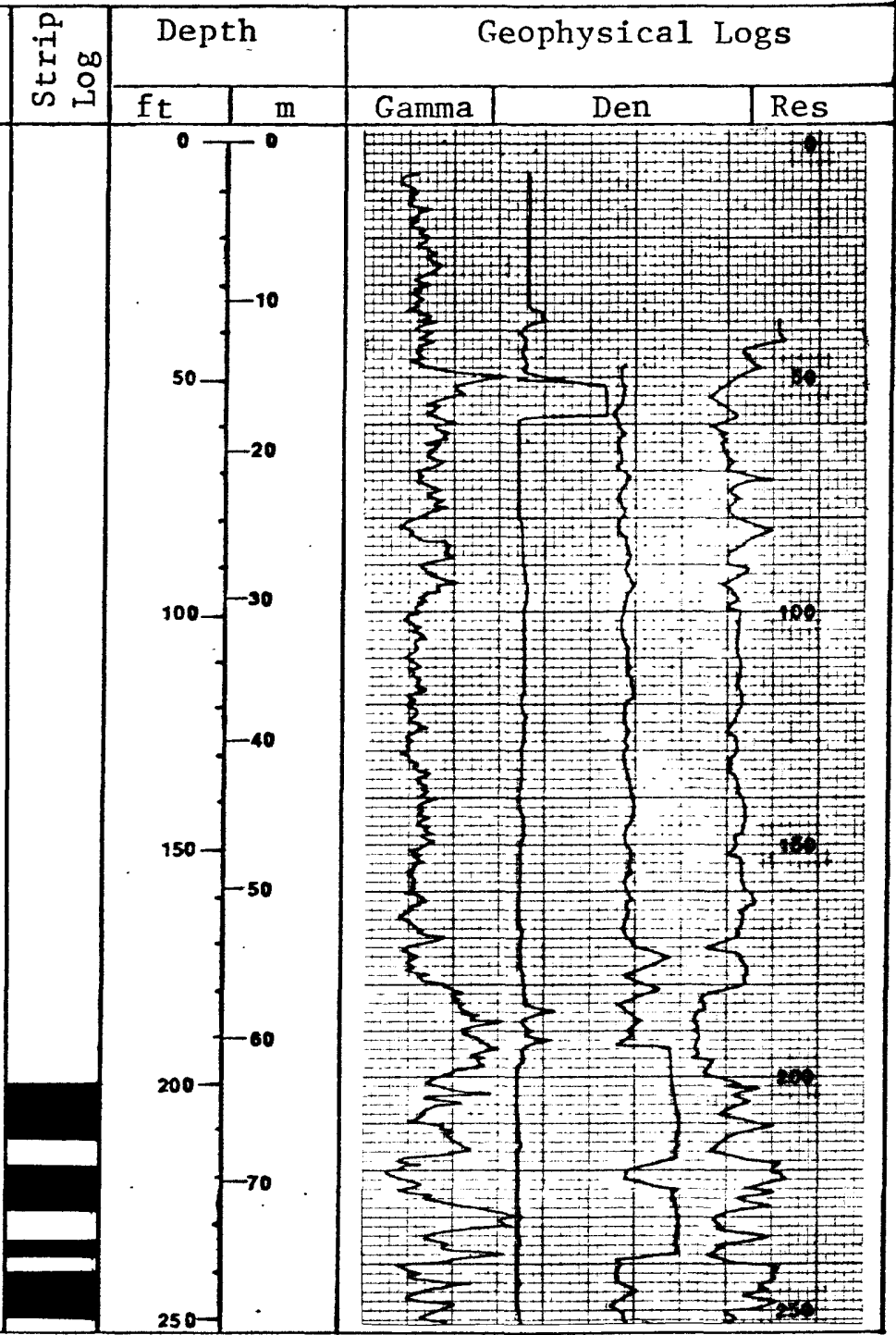




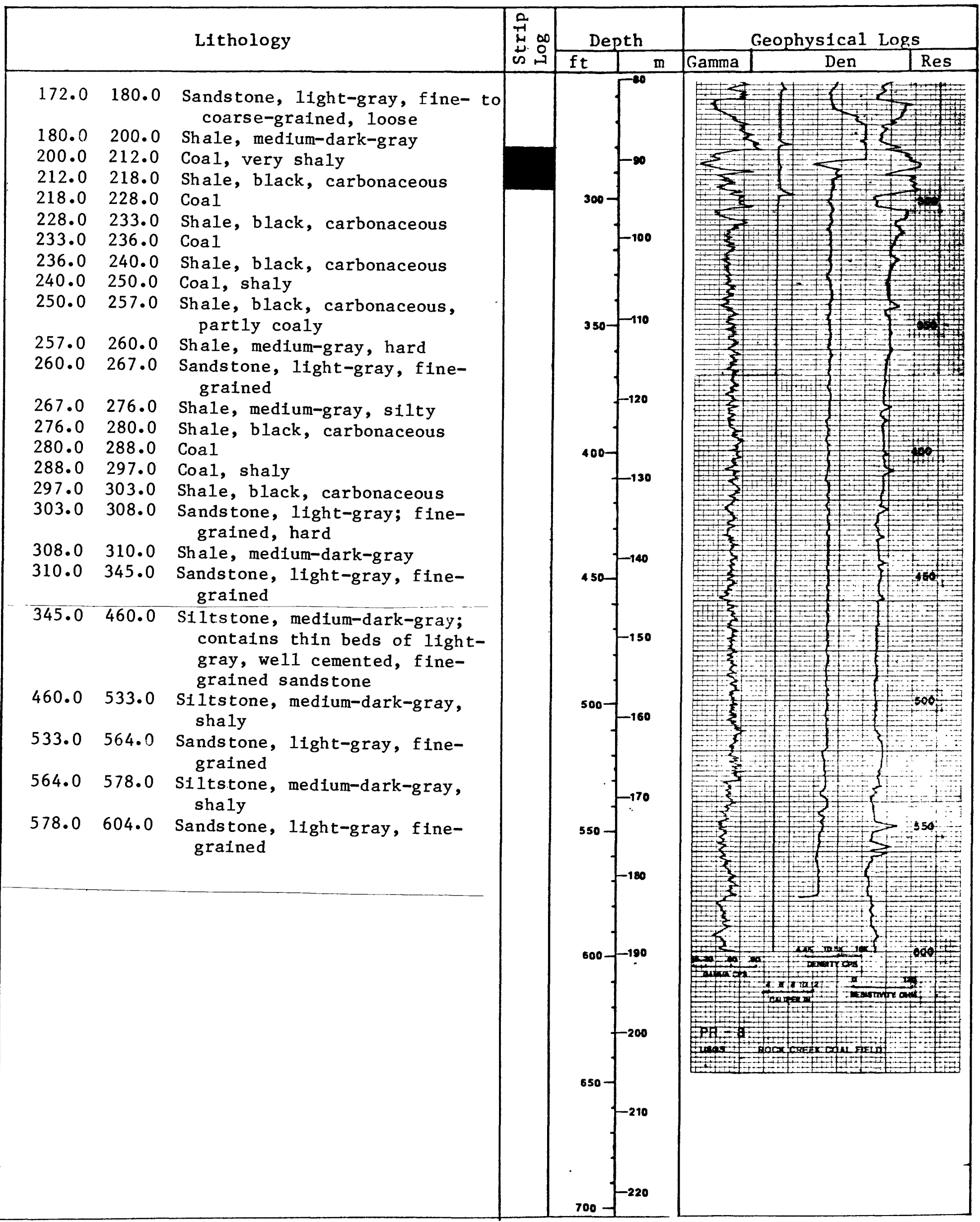




\section{LITHOLOGIC AND GEOPHYSICAL LOGS}

LOCATION NUMBER PR-4

LOCATION SE $\frac{1}{4} \mathrm{SE}^{\frac{1}{4}}$ COUNTY Albany

CORED YES

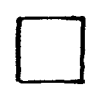

DATE Nov. 15,1978

Sec. 4 T. $19 \mathrm{~N}$. R.

STATE Wyoming

INTERVAL (s)
SURFACE ELEVATION(ft) 7202

Quad. 77 W.

TOTAL DEPTH(ft) 400 .

DRILLING MEDIUM:

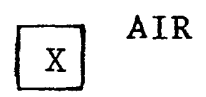

$\square$ FOAM

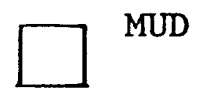

$\square$ WATER OBSERVATION WELL

GEOPHYSICAL LOGS :

Natural Gamma

Gamma Gamma

Resistivity

Caliper
; Scale $10 \mathrm{CPS} / \mathrm{in}$

; Scale 1K CPS/in

; Scale 20 OHM/in

; Scale $1^{\text {"I/in }}$
Logging Speed 15

Logging Speed 10

Logging Speed 15

Logging Speed fpm

fpm

fpm

fpm

0.015 .0 Sandstone, 1ight-brown to brown

15.0 fine to coarse-grained

Lithology

Sandstone, light-brown, finegrained

20.025 .5 Sandstone, 1ight-brownish-gray, fine-grained

25.530 .2 Shale, medium-dark-gray

30.236 .8 Shale, black, carbonaceous

$36.8 \quad 46.5$ Sandstone, light-gray, finegrained, friable

$46.5 \quad 52.0$ Shale, black, carbonaceous

$52.0 \quad 59.0$ Coal, shaly

59.0 61.0 Shale, black, carbonaceous

$61.0 \quad 64.0$ Coal, shaly

64.0 69.6 Siltstone, light- to mediumgray, clayey

69.681 .0 Shale, black, carbonaceous

$81.0 \quad 84.0$ Coal, shaly

$84.0 \quad 89.0$ Shale, black, carbonaceous

$89.0 \quad 94.0$ Coal

94.0 97.2 Shale, black, carbonaceous,

$\begin{array}{lll}97.2 & 99.5 & \text { Coal }\end{array}$ coaly

99.5 103.0 Shale, black, carbonaceous

103.0109 .0 Sandstone, light-gray, finegrained

109.0114 .5 Siltstone, medium-gray, sandy 114.5122 .0 Shale, black, carbonaceous

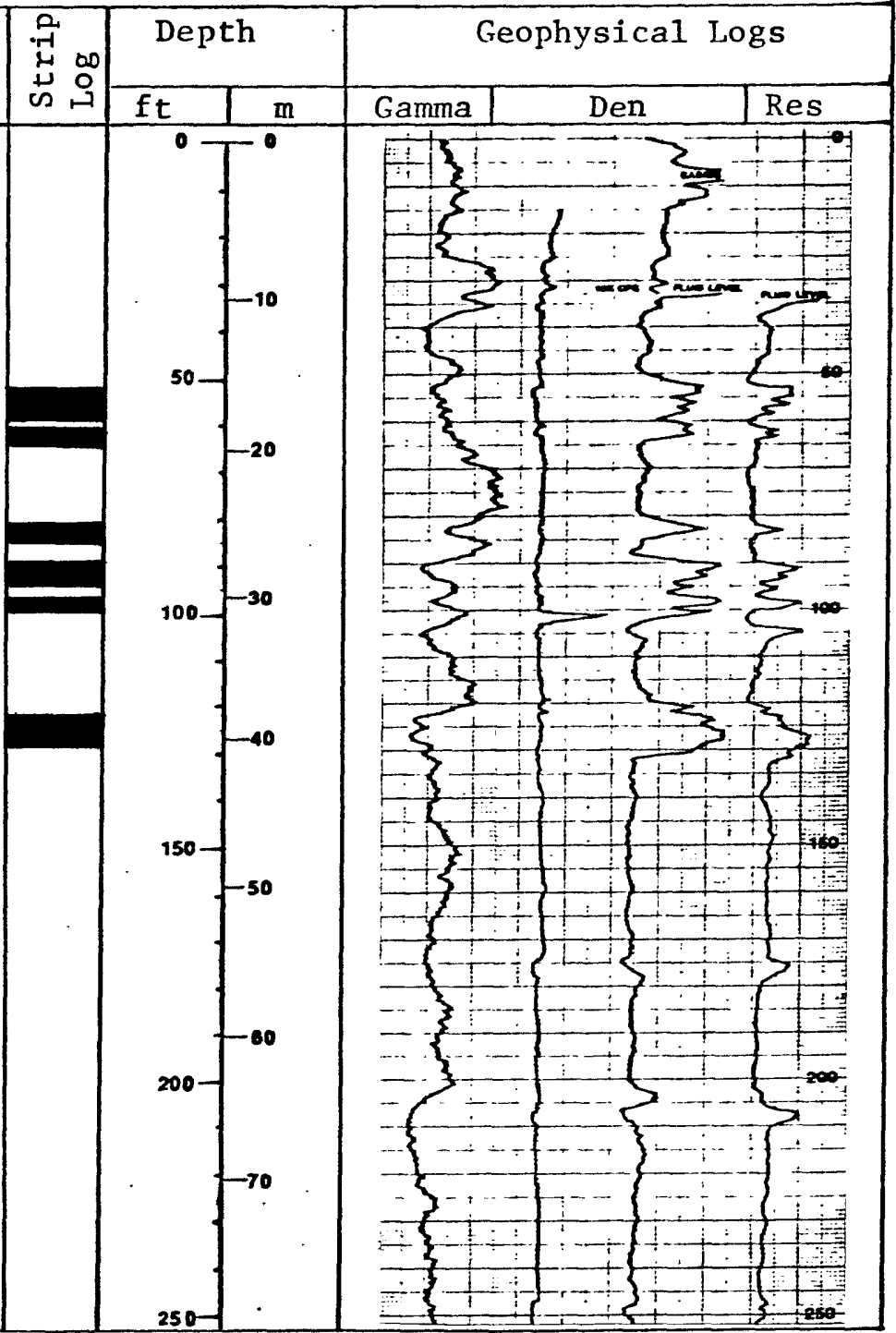




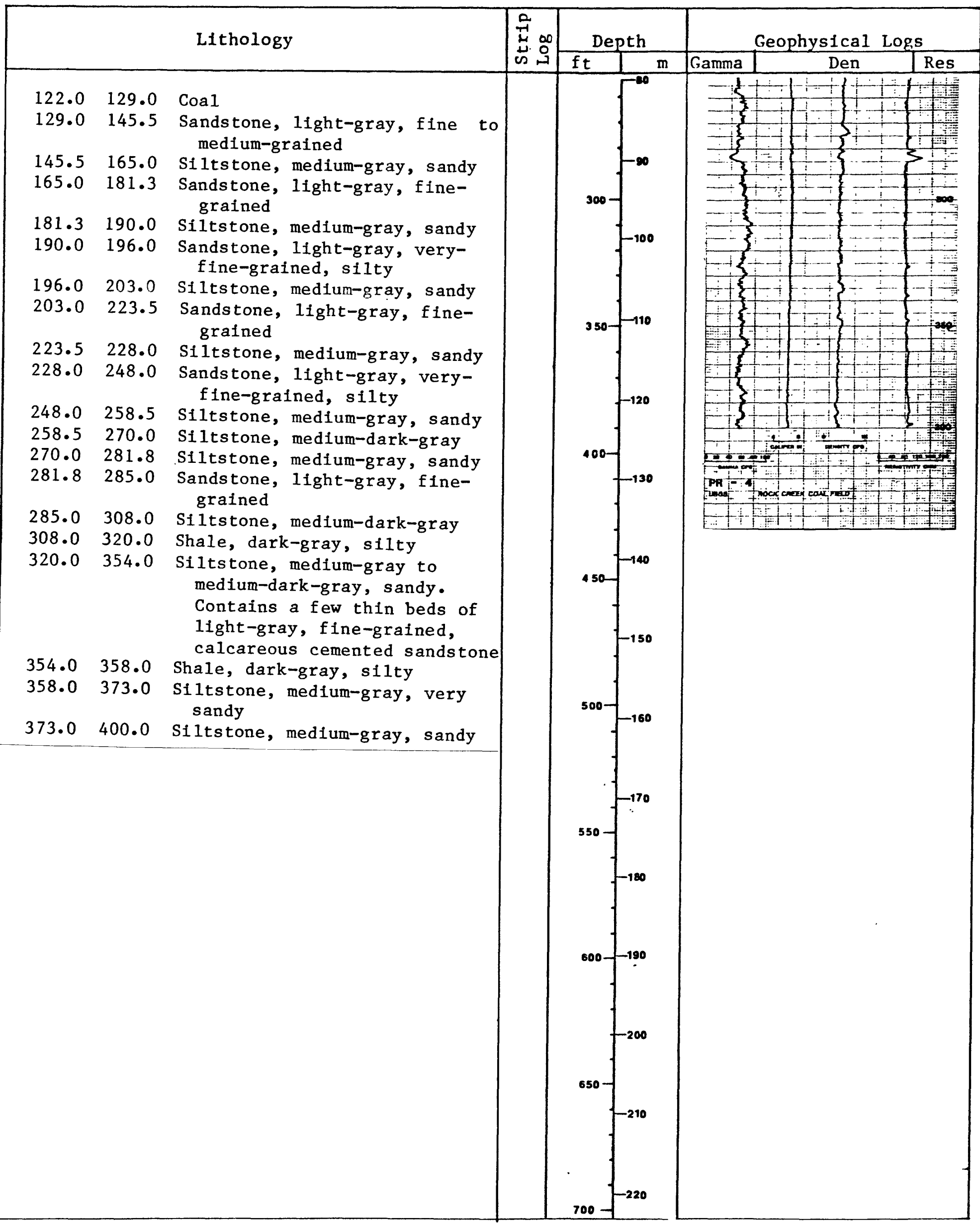




\section{LITHOLOGIC AND GEOPHYSICAL LOGS}

LOCATION NUMBER PR-5

LOCATION NE $\frac{1}{4} \mathrm{NE}^{\frac{1}{4}} \mathrm{SW}^{\frac{1}{4}}$ COUNTY Albany

CORED YES

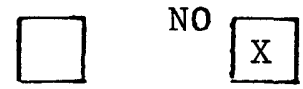

DATE Nov. 25, 1978

Sec. 10 T. 19 N. R. 77 W. Quad. Pierce Reservoir STATE Wyoming TOTAL DEPTH(ft) $\quad 817.5$

INTERVAL (s)

DRILLING MEDIUM:

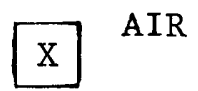

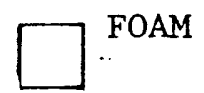

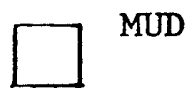

$\square$ WATER OBSERVATION WELL

GEOPHYSICAL LOGS :

Natural Gamma

Gamma Gamma

Resistivity

Caliper
; Scale $12 \mathrm{CPS} /$ in

; Scale

; Scale

; Scale
Logging Speed

Logging Speed

Logging Speed

Logging Speed fpm

$f \mathrm{pm}$

fpm fpm

Lithology

0-0 10.5 Gravel, 1ight- to medium-brown; pebbles mostly of pink feldspar and sandstone. Caliche for first 5 feet

10.522 .0 Siltstone, light-grayish-brown

22.026 .0 Sandstone, light-brown, fine- to very-coarse-grained

26.037 .0 Sandstone, light-brown to brown, fine- to very coarse-grained, conglomeritic

37.041 .0 Conglomerate, reddish-brown

$41.0 \quad 45.0$ Shale, light-gray, silty

$45.0 \quad 54.0$ Siltstone, light- to mediumgray, shaly and sandy

54.058 .0 Sandstone, light-gray, veryfine- to fine- grained

$58.0 \quad 65.0$ Siltstone, light-gray

65.078 .0 Sandstone, light-gray, fine- to medium-grained

78.094 .0 Sandstone, light- to mediumgray, fine-grained, silty

94.0100 .0 Sandstone, light-gray to olivegray, fine- to medium-grained

100.0121 .0 Sandstone, light-gray, coarsegrained, conglomeritic. Granules of pink feldspar

121.0137 .0 Mudstone, dark-greenish-gray, very silty

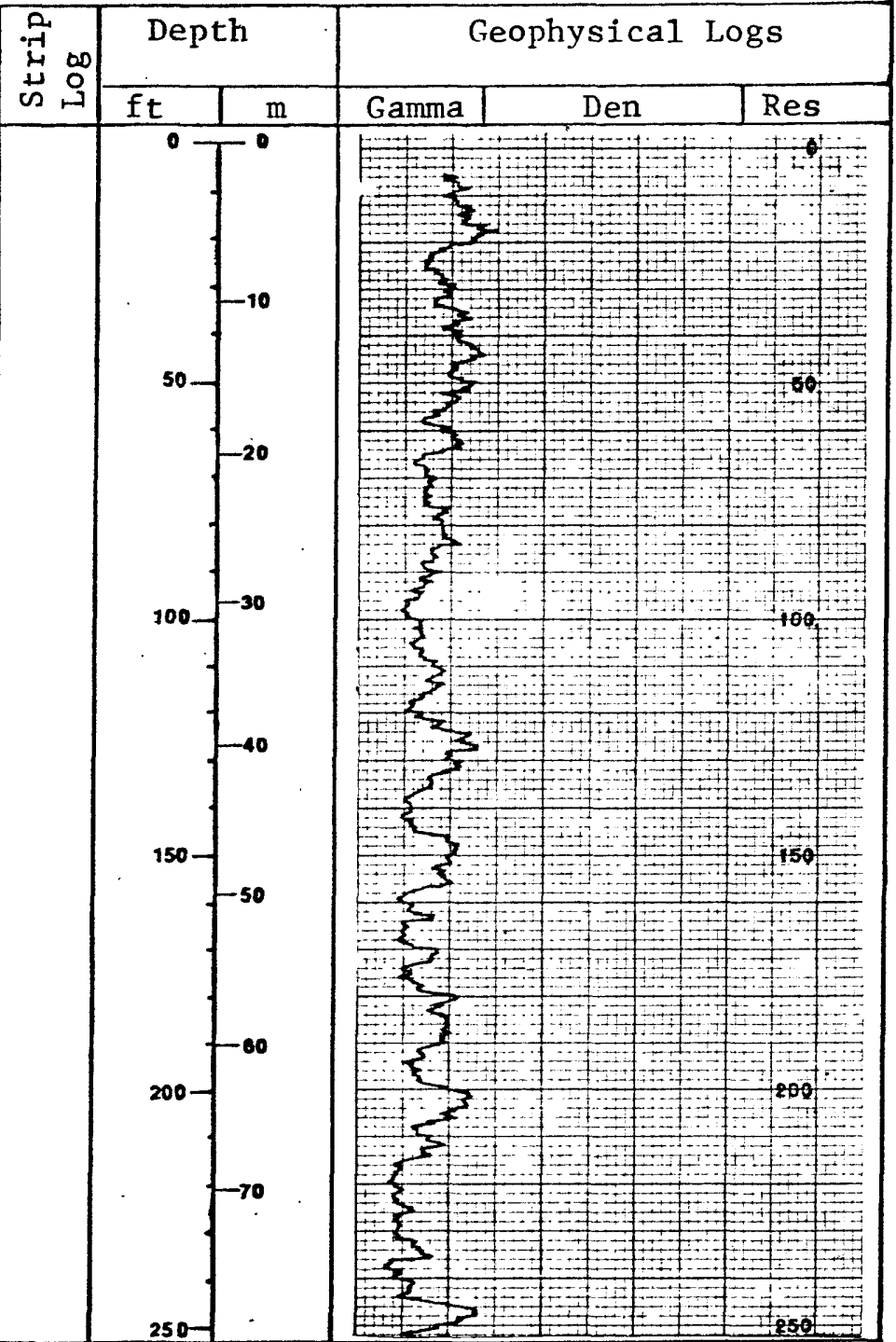




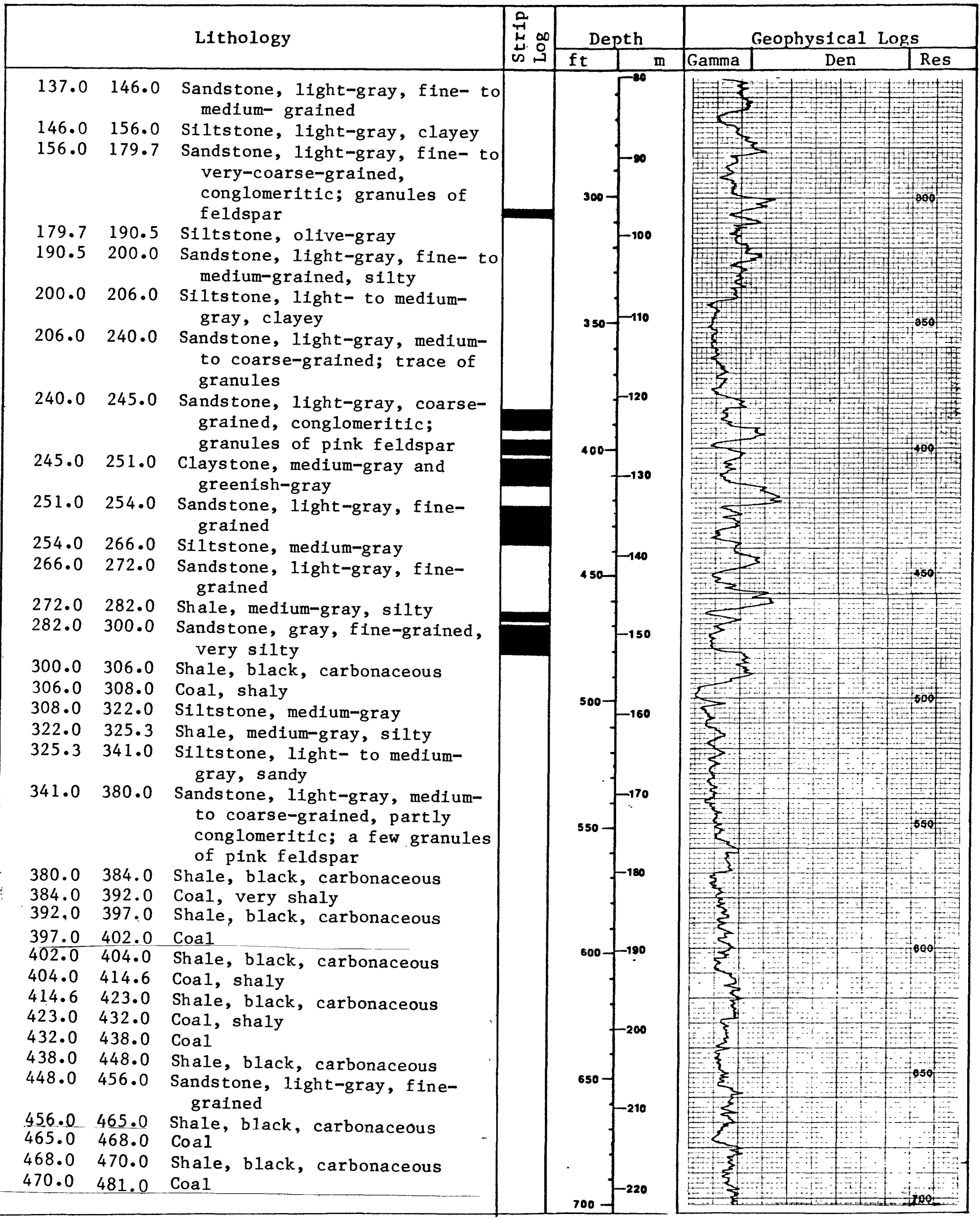




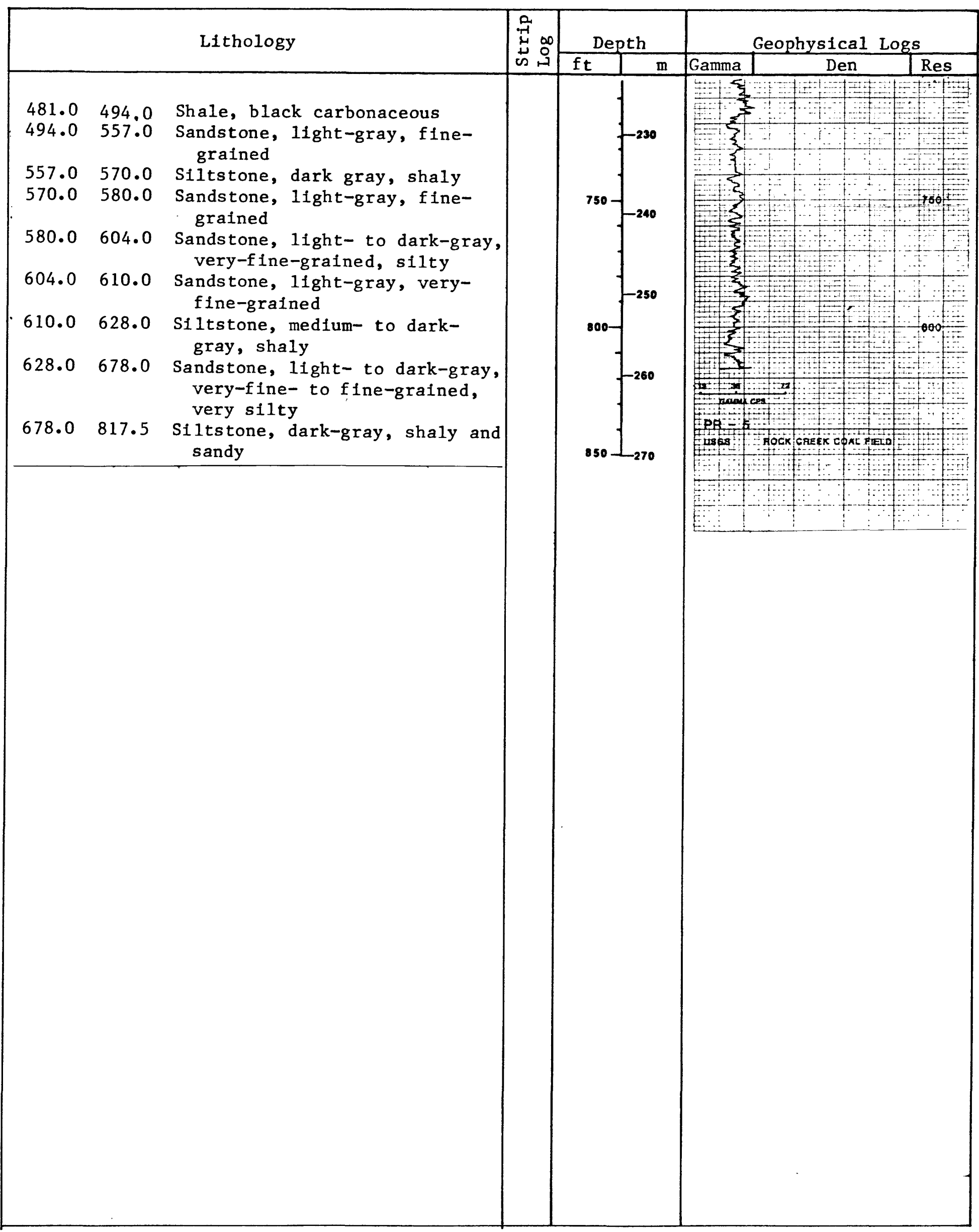




\section{LITHOLOGIC AND GEOPHYSICAL LOGS}

LOCATION NUMBER PR-6

LOCATION SE $\frac{1}{4} \mathrm{SE}^{\frac{1}{4}} \mathrm{SE}^{\frac{1}{4}}$ COUNTY Albany

CORED

YES

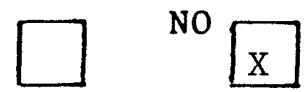

DATE Nov. 16, 1978

Sec. 2 T. 19 N. R. 77 W. Quad. Pierce Reservoir

STATE Wyoming

INTERVAL (s)

DRILLING MEDIUM:
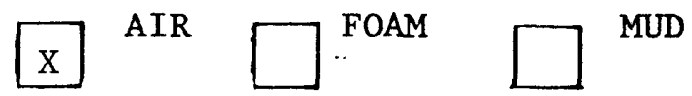

GEOPHYSICAL LOGS :

Natural Gamma

Gamma Gamma

Resistivity

Caliper
; Scale $50 \mathrm{CPS} /$ in

; Scale $1 \mathrm{~K} / 3$ in

; Scale 20 OHM/in

; Scale $1^{\prime \prime} /$ in TOTAL DEPTH(ft) 800 TOTAL DEPTH(ft) 800

SURFACE ELEVATION(ft)

7172

$\square$ WATER OBSERVATION WELL

Lithology

0.015 .0 Gravel and sand, light-yellowbrown, large pebbles of pink feldspar

15.032 .0 Sandstone, 1ight-yellow-gray, fine- to very-coarse-grained

32.038 .0 Sandstone, light-brown, fine- to medium-grained

38.0 43.0 Sandstone, light-gray, fine- to very-coarse grained, conglomeritic. Pebbles of pink feldspar

43.0 119.0 Sandstone, light-gray, fine- to very-coarse-grained, conglomeritic. Granules of feldspar. Large pebbles of granite from 115 to 119 feet

119.0123 .0 Siltstone, medium-dark-gray, sandy

123.0134 .0 Shale, medium-dark-gray

134.0150 .0 Siltstone, medium-dark-gray, sandy

150.0158 .5 Shale, medium- to dark-gray

158.5161 .0 Coal, shaly

161.0168 .0 Shale, medium-dark-gray, silty

168.0177 .0 Sandstone, 1ight-gray; finegrained

$177.0 \quad 185.0$ Shale, gray, silty

185.0191 .5 Sandstone, 1ight-gray, finegrained

191.5202 .0 Siltstone, gray, shaly

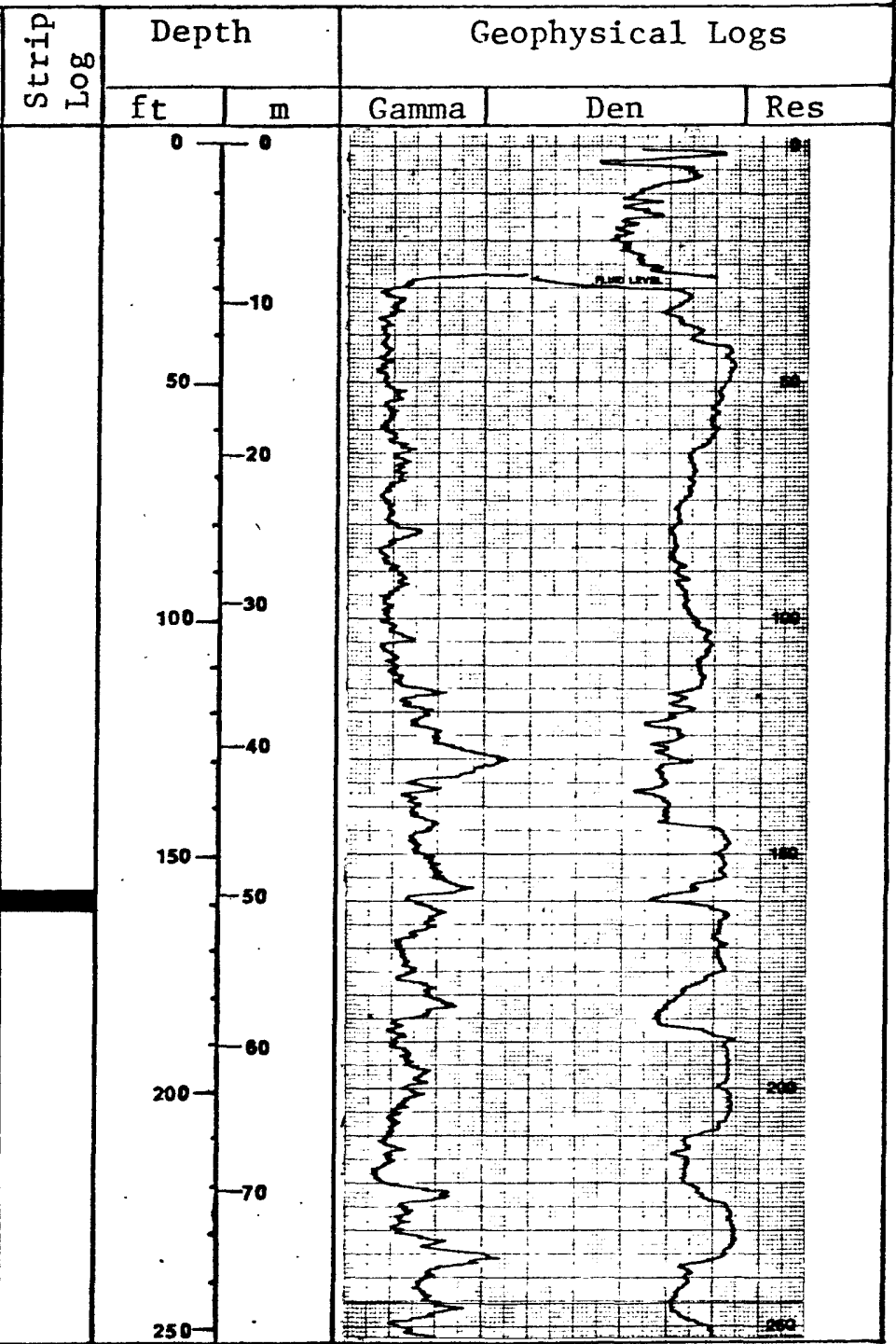

Logging Speed 15 fpm

Logging Speed $10 \quad \mathrm{fpm}$

Logging Speed 15 fpm

Logging Speed 15 fpm 


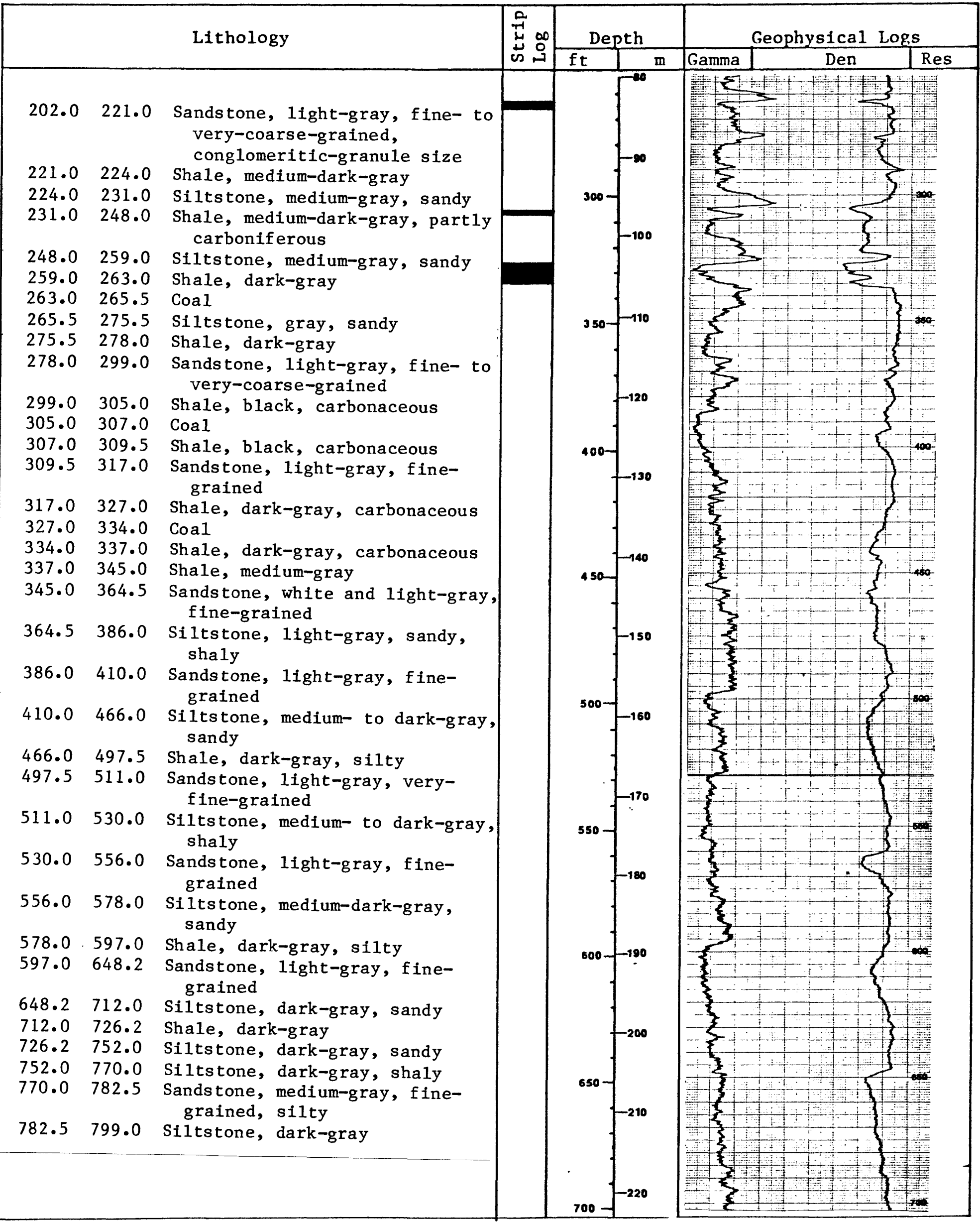




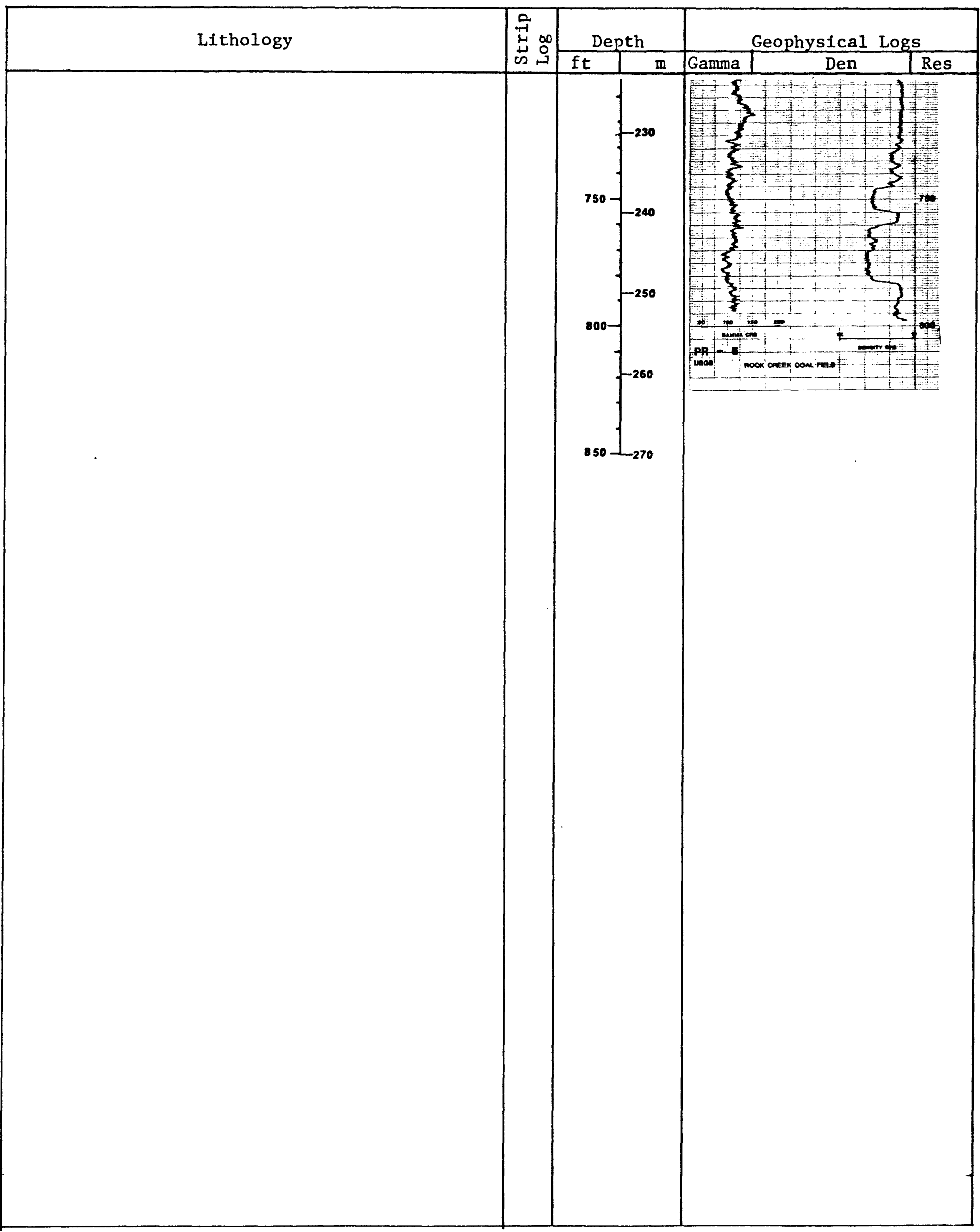




\section{LITHOLOGIC AND GEOPHYSICAL LOGS}

LOCATION NUMBER BH-7-B

LOCATION NW $\frac{1}{4} \mathrm{NW}^{1} \frac{1}{4} \mathrm{SE}^{\frac{1}{4}}$ COUNTY Albany

CORED YES

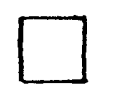

NO<smiles>C1CC2CC12</smiles>

DATE May 20, 1979

Sec. 14 T. $19 \mathrm{~N}$.

STATE Wyoming

INTERVAL (s)
SURFACE ELEVATION(ft) $\quad 7265$

R. 77 W. Quad. Bengough Hill

TOTAL DEPTH(ft)

DRILLING MEDIUM:

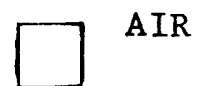

$\square$ FOAM $\mathrm{x}$ MUD

$\square$ WATER OBSERVATION WELL

GEOPHYSICAL LOGS:

Natural Gamma

Gamma Gamma

Resistivity

Caliper
; Scale $160 \mathrm{API} / \mathrm{in}$

; Scale Density G/cc

; Scale $160 \mathrm{OHM} \mathrm{M/in}$

; Scale $1^{\prime \prime} /$ in
Logging Speed

Logging Speed

Logging Speed

Logging Speed

\begin{tabular}{ll}
30 & $\mathrm{fpm}$ \\
\hline 30 & $\mathrm{fpm}$ \\
\hline 30 & $\mathrm{fpm}$ \\
\hline 30 & $\mathrm{fpm}$
\end{tabular}

Lithology

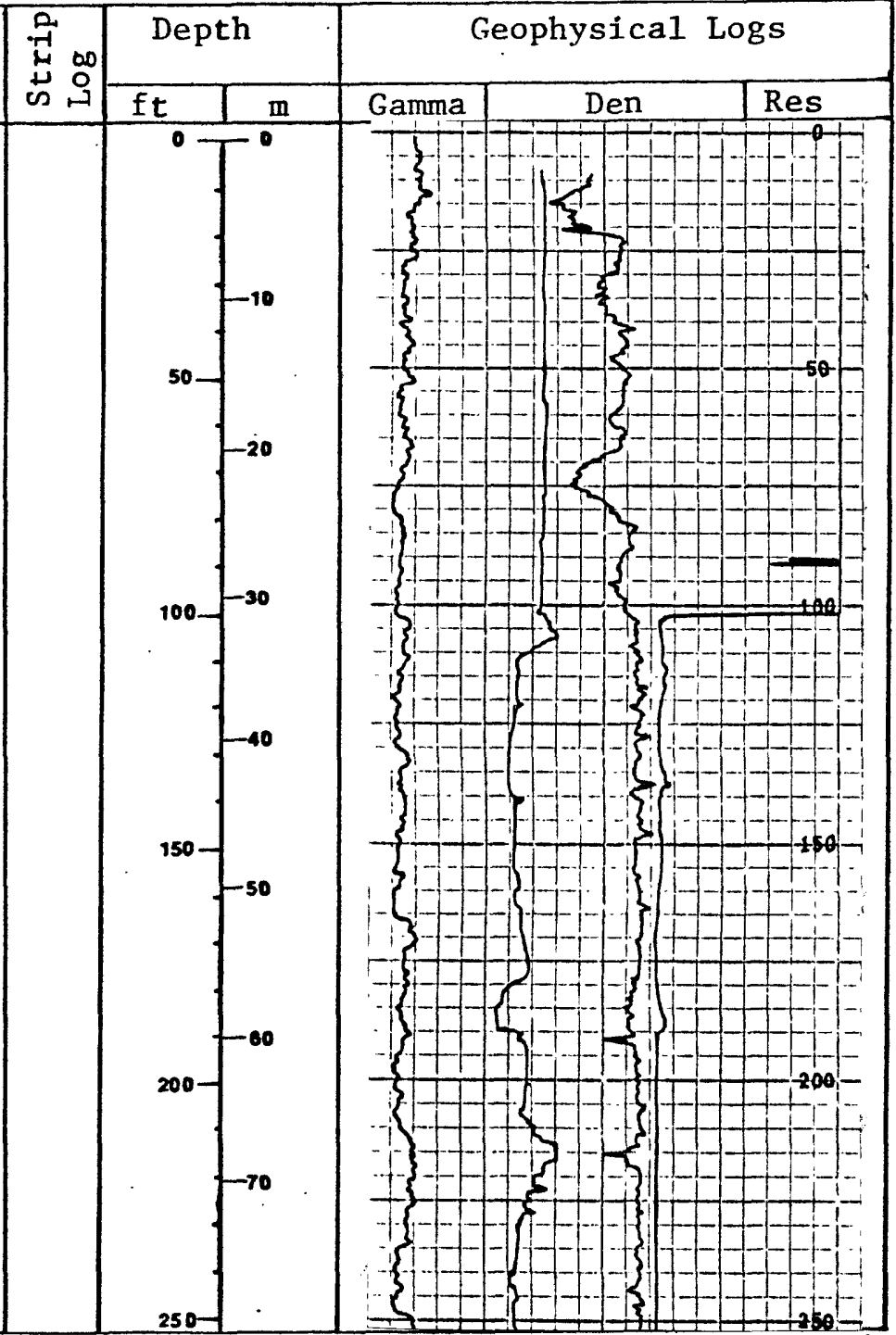

$0.0 \quad 4.0$ Gravel, light-brown

4.0 15.0 Siltstone, light-olive-gray and brownish-red, clayey

15.021 .0 Sandstone, yellow-brown, fine-

21.047 .0 Sandstone, light-brown, fine- to coarse-grained, feldspathic

47.0 65.5 Sandstone, light-gray, fine- to very-coarse-grained, conglomeritic. Many granule size fragments of dark-gray schist and light-gray feldspar

65.5 76.2 Siltstone, medium-greenish-gray, clayey, partly sandy

76.284 .0 Sandstone, light-greenish-gray, chiefly fine-grained

84.0103 .0 Sandstone, gray, fine to verycoarse-grained, conglomeritic, feldspathic

103.0121 .0 Siltstone and sandstone, mediumgreenish-gray, clayey. Sandstone is very fine grained

121.0141 .0 Sandstone, gray, fine- to verycoarse-grained, slightly conglomeritic-granule size, feldspathic 


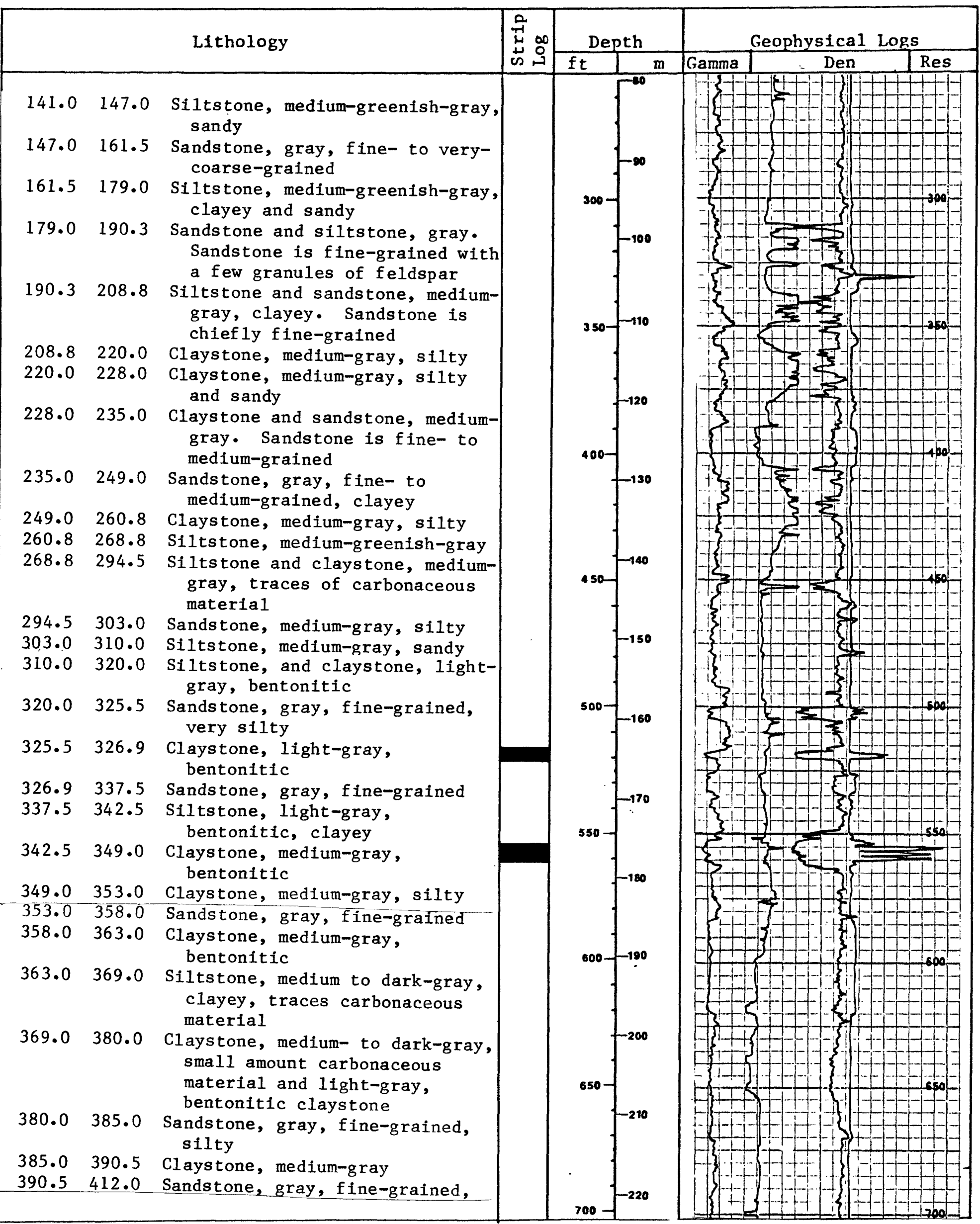




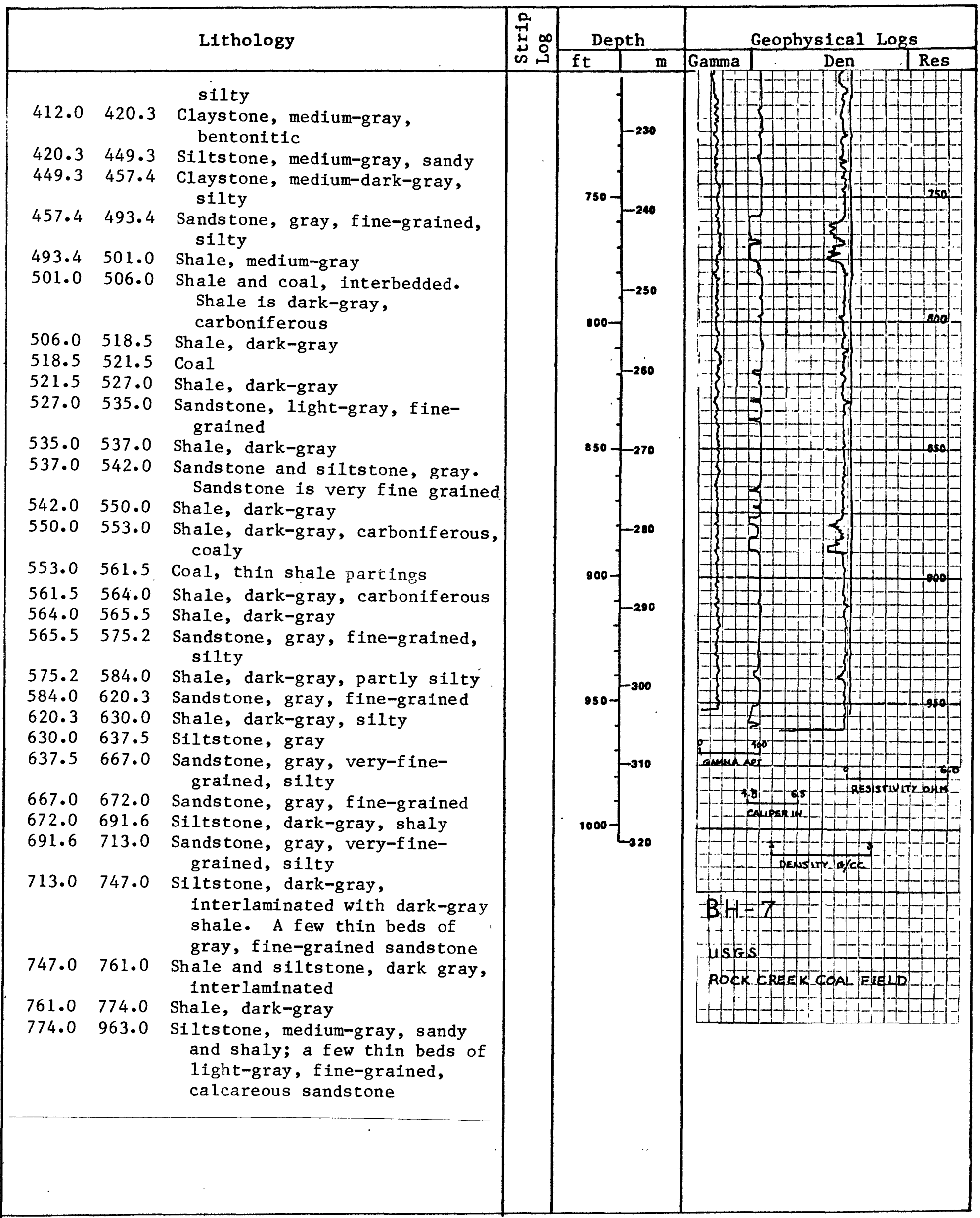

